\title{
Direitos territoriais nas várzeas de Breves, Marajó: novos usos da floresta e distintas percepções sobre o ambiente
}

\section{Considerations on territorial rights in the várzeas of Breves, Marajó: new uses of forest and different perceptions on the environment}

Andrei Cornetta - Doutorando pelo Programa de Pós-Graduação em Geografia Humana da Universidade de São Paulo (PPGH/USP); Pesquisador vinculado ao Laboratório de Geografia Agrária da Universidade de São Paulo. E-mail: andreicornetta@usp.br

\section{Resumo}

Tem por objetivo discutir e analisar questões referentes aos direitos territoriais de populações ribeirinhas no que diz respeito a novos usos e significados atribuídos às florestas de várzea, particularmente aquelas banhadas pelo rio Mapuá, município de Breves, ilha do Marajó. Discute-se sobre distintas percepções; a atuação de três grupos sobre o mesmo ambiente e as disputas em jogo que surgem das relações entre comunidades camponesas ribeirinhas, o Estado e suas políticas territoriais e uma empresa privada de negócios ambientais que desenvolve atividade vinculada ao mercado internacional de compensação de gases efeito estufa. Diante dos objetivos traçados, o presente artigo trabalha com uma combinação de levantamento e análise bibliográfica, documental, trabalhos de campo e entrevistas circunstanciadas com os diferentes atores envolvidos com a temática investigada. Assim, discutem-se a partir de uma análise qualitativa as coexistências e os antagonismos nas relações que se estabelecem entre as atividades regulares de comunidades rurais - seus usos econômicos e formas de convivência com a floresta amazônica -, a atual política de regularização fundiária destinada às áreas de várzea (particularmente às que são parte do Patrimônio da União) e a introdução de projetos de compensação de gases efeito estufa, especificamente os denominados REDD+ (Redução das Emissões por Desmatamento e Degradação Florestal).

\section{Palavras-chave}

Direitos Territoriais. Floresta de Várzea. Ambiente. Questões Agrárias.

\begin{abstract}
This paper aims to discuss and analyze issues related to territorial rights of ribeirinhos with regard to new uses and meanings attributed to várzeas forests, particularly those bathed by Mapuá river, Breves, Marajó Island. This discussion brings forth different perceptions of three groups on the same environment and disputes that arise from relations between ribeirinhos, the State and its territorial policies and environmental businesses linked to the carbon market. Given the established objectives, this paper presents a combination of survey and literature review, document, field work and detailed interviews with the different actors involved with the theme researched. Therefore, coexistences and antagonisms in the relations established between the regular activities of rural communities - their economic uses and ways of living with the Amazon forest -, the current land policy aimed at várzeas and the introduction of a REDD+ project (Reducing Emissions from Deforestation and Forest Degradation) are discussed from the point of view of a qualitative analysis.
\end{abstract}

\section{Keywords}

Territorial rights. Várzeas Forest. Enviroment. Agrarian Issues. 


\section{INTRODUÇÃO}

A partir de registros histórico-geográficos que evidenciam uma ancestralidade anterior à colonização europeia, uma cultura que se faz presente nas populações amazônidas de hoje - e que estudos arqueológicos demonstram se tratar de uma cultura milenar ${ }^{1}$ - este artigo busca refletir sobre novos usos atribuídos às florestas, especificamente as relações entre negócios ambientais vinculados às mudanças do clima, notadamente os vinculados aos "serviços florestais", e comunidades marajoaras, particularmente aquelas que habitam as margens do rio Mapuá, município de Breves, ilha do Marajó.

Questionam-se aspectos do direito histórico aos territórios da população descendente dos índios insulares por meio da análise crítica dos atuais interesses sobre as florestas. Além dos novos negócios e usos da floresta que surgem no contexto das mudanças globais do clima - especificamente os projetos mitigatórios de emissões de gases efeito estufa, como o REDD $+^{2}-$ analisa-se a atual política fundiária aplicada às várzeas do Marajó, onde ambas as ações trazem desdobramentos significativos para famílias que sobrevivem dos recursos das águas, várzeas e florestas.

Busca-se, assim, entender e discutir as coexistências e os antagonismos nas relações que se estabelecem entre três grupos analisados e que estão envolvidos diretamente com as questões acima: 1) camponeses ribeirinhos, detalhadamente famílias que habitam as margens do rio Mapuá, município de Breves; 2) Secretaria do Patrimônio da União (SPU), que detém a dominialidade das áreas de várzea consideradas terras públicas; 3) empresa de negócios ambientais que possui uma área particular de 92 mil hectares ${ }^{3}$

1 Pesquisas arqueológicas realizadas nos municípios de Breves, Gurupá e Melgaço apresentam sítios do período pré-colonial, onde os principais vestígios são fragmentos de cerâmica, além de terra preta, ocasionalmente. Segundo estas pesquisas, estes sítios apresentam testemunhos das primeiras ocupações sedentárias no arquipélago do Marajó, com datas que poderiam estar entre 7 e 4 mil anos antes do presente, por comparação com sítios semelhantes no baixo Amazonas e no litoral Atlântico amazônico. Ver: MARTINS, C. P.; SCHAAN, D. P.; SILVA, W. F. Arqueologia do Marajó das florestas. Fragmentos de um desafio. In: SACHAAN, D.; MARTINS, C. P. (Org.) Muito além dos campos: arqueologia e história na Amazônia Marajoara. Belém: GKNORONHA, 2010. p. 10

2 Os denominados "REDD+", são projetos que possuem a função de produzir biomassa e consequentemente estocar, ou fixar, carbono no tecido lenhoso das árvores. Após a quantificação do carbono estocado e o cumprimento de uma série de exigências técnicoburocráticas, os participantes do projeto podem pleitear créditos compensatórios de carbono e negociá-los nos mercados ad-hoc ou diretamente com empresas que necessitam (ou querem voluntariamente) compensar suas emissões de gases efeito estufa.

3 A dimensão exata da referida área é controversa. Em depoimentos de representantes da empresa e dos documentos oficiais do referido projeto REDD+, fala-se em 98 mil hectares. Porém, com a criação da RESEX do Mapuá, em 2005, uma parcela desta área foi incluída dentro da Unidade de Conservação. 
que se sobrepõe ao território de famílias ribeirinhas do Mapuá, onde a empresa desenvolve um projeto de REDD+.

A partir dos referidos grupos, discutem-se as disputas em jogo, os distintos significados atribuídos à floresta de várzea e conflitos territoriais em torno dos recursos de um ambiente afeiçoado ${ }^{4}$ pelas populações amazônidas insulares e varzeiras.

Este artigo divide-se em duas partes. Além desta introdução, no texto a seguir, discutem-se aspectos históricos e geográficos da formação territorial da ilha do Marajó, especificamente a porção correspondente à microrregião "Furos de Breves", local de muitos episódios de extrema relevância para a história colonial do Brasil. Na sequência, analisa-se conjuntamente o projeto de REDD+ desenvolvido em uma "propriedade particular" ao longo do rio Mapuá, e o processo de regularização fundiária movido pela SPU, conforme indicado acima. Trata-se de uma análise em que os diferentes posicionamentos e interesses sobre os recursos das várzeas, assim como suas decorrentes sobreposições territoriais, são considerados processos relevantes quanto a novos desdobramentos em questões agrárias.

Para substanciar teoricamente esta análise, propõe-se como reflexão final deste texto uma leitura em relação às diferentes visões sobre o mesmo ambiente, especificamente as florestas de várzea do rio Mapuá. Para isso, buscase estabelecer um diálogo com os textos de Bateson ([1972] 2000), Levi-Strauss ([1973] 1993), Sahlins ([1976] 2003), Ingold (2000), entre outros, com o intuito de problematizar as relações entre os grupos analisados e as distintas perspectivas e atuações sobre o mesmo ambiente.

\section{NOTAS HISTÓRICO-GEOGRÁFICAS SOBRE “MARAJÓ DAS ILHAS”}

Os Furos de Breves, classificação dada à microrregião situada a sudoeste do arquipélago do Marajó, estado do Pará, foi lugar de muitas expedições de viajantes e cronistas, desde o século XVI, com as primeiras missões da Companhia de Jesus ${ }^{5}$, até recentemente com as pesquisas de campo do zoólogo Paulo Vanzolini ${ }^{6}$.

4 Utiliza-se afeiçoar tanto como sinônimo de moldar, quanto verbo transitivo direto de fazer sentir ou vir a sentir afeto, amizade ou amor por (alguém ou algo); estimar.

5 Para a leitura completa sobre as Missões dos Jesuítas na ilha de Joanes e rio Amazonas, ver: LEITE, S. História da Companhia de Jesus no Brasil. Tomo III. Norte - 1) Fundações e entradas. Séculos XVII e XVIII. Tomo IV. Norte - 2) Obra e assuntos gerais. Rio de Janeiro: Instituto Nacional do Livro, 1943.

6 Uma das viagens de Paulo Emilio Vanzolini nesta região é retratada no filme "Pelo rio das Amazonas" do diretor Ricardo Dias, que documenta uma expedição do zoólogo entre Belém e Manaus, explorando principalmente os canais do baixo Amazonas junto à ilha do Marajó. 
Dada a complexa hidrografia - uma quantidade grande de cursos d'água entrelaçados anastomosados, um emaranhado de furos, igarapés, canais -, essa porção do delta do rio Amazonas, que contorna o sul da ilha do Marajó e se une às águas do rio Tocantins, possui uma navegação extremamente difícil e arriscada, o que a faz ser conhecida pelos navegantes como "região dos mil furos". Por lá passaram os padres João de Sottomaior ${ }^{7}$ e Antônio Vieira no século XVII, João Daniel $^{8}$ no século XVIII, os naturalistas Alexandre Rodrigues Ferreira ${ }^{9}$ em fins do século XVIII, Jean Louis Rodolphe Agassiz ${ }^{10}$ e Henry Walter Bates ${ }^{11}$ no século XIX, entre outros inúmeros exploradores e estudiosos que se interessaram pela Amazônia e pela "ilha dos Nheengaíba"12.

Dentre as principais narrativas sobre a "ilha de Joanes", estão os episódios registrados na obra de Antônio Vieira que viveu na Amazônia entre 1652 e 1661. Nesse período, o padre jesuíta produziu um amplo material sobre as missões da Companhia de Jesus no Maranhão e Grão-Pará, estado até então autônomo do Brasil. Ao lado de suas funções eclesiásticas, Vieira preocupou-se com o reordenamento da legislação indígena elaborando a lei de abolição dos cativeiros injustos, de 9 de abril de 1655, além de celebrar a chamada "pazes dos Mapuá" (hoje Breves, Marajó) de 1659. Esse episódio, registrado no Tomo II das Cartas do Padre Antônio Vieira, narra um dos principais marcos da diplomacia da

\footnotetext{
Os padres João Sottomaior e Salvador do Valle estiveram na "ilha dos Nheengaíba" em missão evangelizadora no ano de 1665 de acordo com os registros das Cartas do Pe. Antônio Vieira. Deixaram junto aos índios uma imagem do Cristo crucificado. Quatro anos mais tarde a imagem seria encontrada por Antônio Viera no rio dos Mapuá. Ver: Vieira (1735, p. 25).

8 Padre e cronista da Companhia de Jesus, João Daniel escreveu entre os anos de 1722 e 1776 uma das principais fontes de informação sobre a Amazônia no período colonial, publicado em 1801 (manuscrito) com o título de "Tesouro descoberto no máximo Rio Amazonas". Somente em 1976 a Biblioteca Nacional estabeleceu a versão definitiva dos manuscritos, incluindo a última parte depositada em Évora. Ver: DANIEL, J. Tesouro descoberto no máximo rio Amazonas. Rio de Janeiro: Contraponto, 2004.

9 Alexandre Rodrigues Ferreira nasceu na Bahia, em 1756, e faleceu em Lisboa, em 1815. Foi nomeado pela Rainha D. Maria I, em 1778, para chefiar a comissão científica encarregada de empreender viagem pelas capitanias do Grão-Pará, Rio Negro, Mato Grosso e Cuiabá. Para a leitura completa desta expedição, ver: FERREIRA, A. R. Viagem filosófica pelas capitanias do Grão-Pará, Rio Negro, Mato Grosso e Cuiabá: 1783-1792 (2 vols.). Rio de Janeiro: Conselho Federal de Cultura, 1971.

10 Em 1865 Agassiz veio para o Brasil comandando a expedição Thayer saindo de Nova York passando pelo Rio de Janeiro, Minas Gerais, Nordeste do Brasil e Amazônia. Sua passagem pela cidade de Breves está relatada em A journey in Braz̧il no capítulo V entre as páginas $154 \mathrm{e}$ 164. Ver: AGASSIZ, L. A journey in Brazil. Boston: Ticknor and Fields, 1868.

11 Naturalista e entomólogo inglês, Henry Walter Bates viveu na Amazônia brasileira entre 1848 e 1859, onde coletou mais de 14 mil insetos. Suas principais descobertas estão registradas em "The naturalist in the river Amazons" de 1863. Ver: BATES, H. W. O naturalista no rio Amazonas. Tradução, prefácio e notas de Candido de Mello-Leitão. Rio de Janeiro: Companhia Editora Nacional, 1944.

12 Maneira como Antônio Vieira se refere à ilha do Marajó. Ver: Viera (1735, p. 22).
} 
colônia e da própria formação territorial do Brasil, apesar da pouca atenção que lhe é dado enquanto evento de relevância geopolítica ${ }^{13}$.

Notadamente, o conjunto dessas crônicas e escrituras é a evidência ${ }^{14}$ de encontros entre culturas que resultaram em genocídios (e epistemicídios ${ }^{15}$ ) para a concretização de um projeto eurocêntrico, sustentado pela perspectiva política do expansionismo, pelo acúmulo e espoliação de riquezas e a catequização de novas almas. Evidentemente, tais ordenamentos dizimaram inúmeras nações indígenas que, "ao se verem forçadas a criar outras táticas de combate e resistência, inventaram novas fronteiras e configurações étnicas, políticas e culturais" (PACHECO, 2010, p. 15).

Entretanto, ao mesmo tempo, tais escrituras podem mostrar uma terceira via entre o etnocentrismo e a relativização cultural $^{16}$, sobretudo em relação ao reconhecimento da autodeterminação dos índios (e que hoje serviria às populações insulares e varzeiras), os quais Vieira considerava, entre todos os homens, os mais próximos filhos de Deus. Estes "encontrados na natureza em estado de fraternidade com plantas e animais dos quais eles se acreditavam descendentes totêmicos” (PEREIRA, 2007, p. 205). Como o historiador marajoara José Varella Pereira sinaliza, "em meio a diversas especulações, as Cartas de Vieira são fonte que os caboclos descendentes dos índios das ilhas têm para argumentar e defender seus direitos" (p. 206). Como bem descreve Vieira (1718) sobre as populações insulares,

[...] cujas terras estão todas senhoreadas, \& afogadas das aguas, sendo muyto contados, \& muyto estreytos os sitios mais altos que ellas, \& muyto distantes huns dos outros, em que os índios possaõ assentar suas povoações, vivendo por esta casa não immediatamente sobre a terra, senão em casas levantadas sobre esteyos [palafitas] a que chamaõ Juráos [jirau], para que nas mayores enchentes passem as aguas por bayxo, bem assim como as mesmas arvores, que tendo as raizes, \& troncos escondidos na agua, por cima della se conservão, \& apparecem, diferindo só as arvores das casas, em que humas saõ de ramo verdes, outras de palmas secas ${ }^{\square 17}$ (VIEIRA, 1718, p. 302).

13 O episódio faz parte da guerra luso-holandesa (1630-1654) e a disputa estratégica pela ilha de Joanes. Para uma leitura mais completa ver: Vieira (1735, p. 41) e Pereira (2007, p. 196; 197).

14 Considera-se evidência aqui na rubrica da retórica como mais adequado ao tema, isto é, uma descrição viva e minuciosa de um objeto, realizada com a enumeração de suas particularidades sensíveis, reais ou fantasiosas.

15 Sobre a ideia de "epistemicídio" ver: SANTOS, B. S.; MENESES, M. P. (Org.). Epistemologias do Sul. São Paulo: Cortez, 2010.

16 Sobre este aspecto, ver: HANSEN, J. A. Para ler as cartas do Pe. Antonio Vieira. Asas da Palavra. Revista de letras, Belém: Unama, v. 10, n. 23, 2007.

17 No referido filme citado na nota 7, Vanzolini faz uma descrição da arquitetura ribeirinha com características semelhantes à feita por Vieira, no século XVII: "A casa amazônica vista superficialmente é uma casa muito simples e despretensiosa. No entanto, ela é resultado de uma tecnologia extremamente apurada e sofisticada, especialmente no que diz respeito à escolha 
As terras que hoje formam a unidade de onze comunidades às margens do Mapuá, incluindo a comunidade Bom Jesus (onde encontramos os interlocutores dessa pesquisa), pertencem historicamente a inúmeras famílias que se estabeleceram na região, cuja ancestralidade milenar, provavelmente, de um lado, dos Nheengaíba e, uma ancestralidade mais recente, porém secular, de cearenses que migraram para região para trabalhar nas colocações de borracha no fim do século XIX, início do XX.

Grosso modo, esse processo histórico característico da formação territorial da Amazônia, deu origem a um campesinato ${ }^{18}$ de várzea, cuja reprodução de seus territórios tem se baseado no uso múltiplo dos recursos, envolvendo agricultura, pesca, extrativismo de recursos florestais, caça, criação de animais de pequeno porte, além da bubalinocultura e do gado bovino, criados em pequena escala.

A dinâmica socioespacial dada pela insularidade é um dos principais traços que marca o arquipélago do Marajó, assim como da chamada zona Guajarina, onde está localizada a capital Belém. Essa dinâmica, que dá a tônica à economia e cultura regional, inclui um intenso fluxo entre ilhas e áreas urbanas de produtos extrativos dos rios e do manejo florestal. Além disso, fluências políticas, culturais e outras que são próprias às águas, compõem os distintos fluxos viabilizados pela rede hidrográfica do estuário amazônico.

As atividades que se desenvolvem em grande parte neste estuário estão diretamente ligadas ao movimento diário e sazonal das águas. Como ressalta o historiador Leandro Tocantins (1961, p. 249), “o primado social dos rios [...] revela-se nos múltiplos aspectos da vida amazônica". Sobre o aspecto que envolve a vida material e simbólica de populações ribeirinhas, ou varzeiras, Castro (2000,

dos materiais. Por exemplo, uma casa como esta ela começa tendo os esteios. Os esteios têm de ser de uma madeira incorruptível [para suportar a elevação do nível da água] e neste caso elas são de acapu. Depois vem a armação do telhado, o ligamento do telhado e depois as paredes e a cobertura. As paredes, neste caso, são de guaruba-cedro, uma madeira leve, fácil de cerrar e que dura muito. Com uma demão de tinta ela dura 30, 40 anos. E o telhado, do meu ponto de vista, é o mais interessante. Por que na Amazônia de ponta a ponta, usa-se a mesma palmeira para se fazer telhado. Os livros trazem como nome vulgar dela como ubuçu, só que o povo só fala buçu. O buçu é uma palha que dura 30 anos e não dá inseto. Todo mundo pensa nas riquezas químicas da mata amazônica, pensando na cura do câncer, do AIDS, etc., e ninguém pensa nessas coisas simples. Por exemplo, que substância conteria o buçu que não dá inseto, que não é atacado por insetos ao longo de 30 anos?" (VANZOLINI, P. No rio das amazonas. [29'40”]).

18 O termo campesinato aqui é tratado de maneira semelhante ao que Hébette trata em sua obra. Isto é, e resumindo, "para designar um modo de vida - ou uma forma de organização social de pequenos produtores rurais construídos sobre relações familiares e de vizinhança. A opção por esse termo, retomado dos clássicos europeus das análises sobre a questão agrária no final do século XIX e início do XX, é uma tomada de posição frente à tendência mais recente de se analisar a agricultura praticada por esses produtores a partir de modelos teóricos da agricultura empresarial/capitalista ou, na melhor das hipóteses, procurando reconstruir a especificidade de seu modo de produzir - ou seu sistema de produção - de forma desarticulada de seu modo de vida" (HÉBETTE, 2002, p. 9). 
p. 169) ressalta que "o uso dos recursos da floresta e dos cursos d'água estão, portanto, presentes em seus modos de vida, como dimensões fundamentais que atravessam gerações e fundam uma noção de território, seja como patrimônio comum, seja como de uso familiar [...]".

Tal fato implica na configuração de direitos relativos ao reconhecimento do território ocupado ou, no dizer de Almeida (2008), "na configuração da terra tradicionalmente ocupada"19. O modo de vida dos moradores do rio Mapuá estão marcadas por suas práticas habituais com um profundo enraizamento com a várzea e os corpos d'água, valorizado pelos saberes ancestrais e pelos laços de parentesco e vizinhança, característicos da vida camponesa ${ }^{20}$.

A origem, segundo diversos autores ${ }^{21}$, está nos movimentos migratórios durante o período de grande exploração da borracha, quando inúmeros nordestinos, sobretudo do semiárido, vieram trabalhar nas colocações de borracha da Amazônia. Foi a partir do declínio da borracha amazônica no mercado internacional - muito em função das produções em linha do leste asiático, e das alterações sofridas no sistema de aviamento, como o maior grau de monetarização -, que surgiram outras dinâmicas para os que permaneceram nas colocações. O desenvolvimento de uma agricultura de subsistência, criação de pequenos animas, a pesca, além da coleta de frutos e produtos extrativos direcionados para o mercado; peixe, açaí, palmito, castanhas, madeira, timbó, entre outros.

\section{SOBREPOSIÇÕES TERRITORIAIS E INTERSEÇÕES POLÍTICAS NO RIO MAPUÁ}

Rios, furos, estreitos, igarapés, igapós, várzeas, açaizais, imensos aguaçais, florestas, são lugares comuns onde se inscrevem a cultura das famílias que vivem nas margens do rio Mapuá, assim como em grande parte do arquipélago do Marajó. Como mencionado acima, em geral, estas famílias ribeirinhas, descendentes de índios da nação Nheengaíba, colonizadores europeus e migrantes da borracha, têm na várzea um ambiente síntese de sua cultura que se reproduz entre os corpos

19 De acordo com Almeida (2008), "nesta diversidade de formas de reconhecimento jurídico das diferentes modalidades de apropriação dos recursos naturais que caracterizam as denominadas 'terras tradicionalmente ocupadas', o uso comum de florestas, recursos hídricos, campos e pastagens aparece combinado, tanto com a propriedade, quanto com a posse, de maneira perene ou temporária, e envolve diferentes atividades produtivas exercidas por unidades de trabalho familiar, tais como: extrativismo, agricultura, pesca, caça, artesanato e pecuária" (p. 37; 38).

20 Sobre tais características, ver: SHANIN, T. "A definição de camponês: conceituações e desconceituações”. Estudos CEBRAP, n. 26, 1980.

21 Ab’Saber (1996), Lima (1933), Hebétte (2004), Santos (1980), Tocantins (1961), e outros. 
d'água e a floresta. Como bem mostram as Cartas do Padre Antônio Vieira, em meados do século XVII, este ambiente, alagadiço e de densa floresta, é central para as populações amazônidas, sobretudo para a cultura marajoara ${ }^{22}$.

As várzeas do Mapuá e seus recursos vêm sendo alvo de intensas disputas e interesses desde a guerra luso-holandesa no século $\mathrm{XVII}^{23}$, passando pelas colocações de borracha na região, instaladas em princípios do século XX, a exploração madeireira que atravessa o século XX até os dias de hoje com os interesses diversos - incluindo os "serviços ambientais" 24 - sobre os recursos da várzea.

Com a intensificação da economia gomífera na Amazônia, juntamente com o grande número de trabalhadores que se deslocaram para a região, inúmeros comerciantes foram atraídos pelas oportunidades de um mercado doméstico em crescimento. Grande parte desse comércio, baseado no sistema de "aviamento", tipo de venda de mercadoria a prazo, cujo pagamento será feito em produtos extrativos dentro de um tempo determinado (MCGRATH, 1999), implicou em uma série de desdobramentos para as famílias do Mapuá. Como relata um dos moradores da comunidade Bom Jesus.

Eu nasci aqui mesmo [Mapuá]. A minha bisavó veio dos indígenas. Ela era uma das tribos indígenas daqui do Mapuá [...] A minha avó era cor morena, cabelo bem liso, morreu com 108 anos. Aqui tinha o cearense, tinha o indígena, aqui tinha os caboclos. Aí mistura o cearense com todo esse tipo de sangue, tem uma grande polêmica que foi a origem dos índios que se afastaram do Mapuá no tempo dos coronéis [...]. Primeiro veio os coronéis, daí veio os outros para montar seus comércios que faziam o trabalho da borracha, da seringa e que pagava o preço que bem entendia ${ }^{25}$.

Os trabalhadores entregavam toda a sua produção em troca de mercadorias manufaturadas, porém, essa produção nunca atingia o valor gasto nas chamadas "cantinas", com toda a mercadoria de que necessitavam para manter suas famílias.

22 Ver, por exemplo, Vieira (1718, p. 301).

23 No período, o peixe-boi era o principal produto de exportação para Holanda sendo comercializado com os índios Nheengaíba. Para maiores detalhes, ver: Vieira (1735, p. 26).

24 Existem diversas definições do que sejam os serviços ou bens ambientais. Os documentos da Organização para a Cooperação e o Desenvolvimento Econômico (OCDE) têm tratado do assunto e abordado tais atividades como aquelas que têm por finalidade auferir, prevenir, mitigar ou corrigir danos ambientais causados à água, ao solo, ao ar, incluindo os problemas relacionados a desperdício, poluição e danos aos ecossistemas. Para maiores detalhes ver: OCDE. Environmental goods and services. An assessement of the environmental, economic and development benefits of further global and trade liberalisation. Paris: OECD/OCDE, 2000.

25 Entrevista com o vice-presidente da Associação dos Moradores Extrativistas do Mapuá (AMOREMA). 
A relação de paternalismo e clientelismo entre extrativistas, comerciantes e proprietários de terras, obrigava muitas famílias a liquidar suas dívidas entregando sua terra, seu sítio, sua posse (HERRERA, 2003, p. 51). Este processo de espoliação implicou em mudanças significativas no Mapuá, dando origem aos primeiros "proprietários" que concentram grandes áreas de terras nesta região, como relembra um dos moradores.

Consta na nota que o meu pai tinha que eles tiravam uma comissão muito alta e a gente não sabia. Então, eles que moravam aqui, os poderosos, consta que cada um morador, meus avós, eles tinham um terreno aqui. Aí quando chegava no fim do ano, o cara não pagava conta com a borracha. Ele ralhava os fregueses, aí ia para cidade dele, era o prefeito nesse tempo. Ele mandava cadastrar tudinho e tomava a terra do pessoal, aí ele fez um terreno só, diz que foi assim o negócio ${ }^{26}$.

Relações híbridas de trabalho, como verificadas na pesquisa de campo, são exemplos de intersecções históricas que reproduzem, ainda hoje, uma lógica semelhante à economia existente no período gomífero. Traços desse sistema econômico são encontrados atualmente em certas localidades ao longo do rio Mapuá, apresentando transformações, sobretudo em relação à circulação monetária e à fusão de relações de trabalho arcaicas com formas contemporâneas. O aviamento, por exemplo, funde-se ao trabalho assalariado e reforça as relações assimétricas que marcam a formação econômica e territorial da Amazônia.

Quanto à organização espacial, os "barracões"27, por exemplo, são marcas na paisagem que apontam para a herança do período gomífero e que ainda exercem funções semelhantes de controle e dominação sobre as colocações. No rio Mapuá, as particularidades desse domínio territorial aparecem assim:

[Quando tinha madeireira, tinha cantina?] Tinha dos (Félix). Porque foi assim, os (Félix) venderam isso aqui, mas eles nunca desistiram. [Tão aí ainda?] Em frente lá a boca [do rio]. Aí o que acontece, eles tinham dois comércios aqui dentro. Mas assim mesmo ninguém podia tirar nada. Nós que morava nas terras não podia tirar nada. Uma vez eu vendia uma farinha lá para o (São Miguel dos Macacos). A gente chama o quilo. São 4 latão de farinha o quilo que a gente chama. Foi 16 latas eu vendi. Aí ele veio aí e despediu nós. Falou que ia mandar prender meu pai. Eu era menino, aí eu disse para ele que me prendesse que era eu que tinha vendido a farinha pro

26 Entrevista com um morador da comunidade Bom Jesus.

27 O barracão, ponto comercial e de moradia do "patrão" localizou-se na "boca" dos rios. Era o ponto onde os fregueses faziam a "quinzena", entregando sua produção extrativa (geralmente quinzenal) para o acerto das "contas", abastecendo-se de alimentos, de munição e de instrumentos de trabalho para uma nova jornada na floresta. [...] A partir da "boca" do rio, o seringalista detinha o domínio completo do comércio do rio, não permitindo que "regatões" e "marreteiros" mantivessem relações comerciais com a sua freguesia (OLIVEIRA Jr., 1991, p. 57). 
meu pai. Aí ele ficou bravo e disse que ia me prender, que eu era moleque saliente. "O senhor paga o que nóis tem que nóis sai. Não precisa o senhor mandar prender a mim, nem a meu pai. Nóis sai aí. Pague aî’.Nóis tinha 10 roça. Nóis trabalhava com muita roça. Muita produção grande nóis tinha de farinheiro. E ele ficou demais valente com nóis ${ }^{28}$.

As relações de exploração como estas têm diminuído significativamente nos últimos anos pelos mais variados motivos. Segundo alguns relatos, o pagamento de "tributos" para o uso da área de várzea diminuiu de maneira significativa nos últimos anos, em grande parte devido ao conhecimento de que as áreas de várzea são da marinha, portanto, públicas.

De certa forma, onde você tinha um conflito, hoje você chega em algum lugar [...] que o cara tem o documento da terra, ele sabe que aquilo é dele, que não pertence a outra pessoa, como se tinha muito essa questão: "Não, eu trabalho nessa terra, mas a terra não é minha". O que eu produzo eu só posso vender para o meu patrão. Então essa coisa também foi quebrada, aquela questão de que, por exemplo, se eu tirar agora na safra dez latas de açaí, cinco eu tenho que dar para o meu patrão [sistema conhecido como "meia"] e as outras cinco eu tenho que vender para ele. Isso acontecia no Mapuá ${ }^{29}$.

Todavia, as disputas entre pretensos donos e ribeirinhos posseiros do Mapuá se dão ainda hoje, sobretudo pela retirada de madeira e pela extração de açaí. Até meados do século XX, pode-se dizer que a produção do açaí era predominantemente extrativista, objetivando o consumo doméstico e com pouca venda de excedente (SANTANA; CARVALHO; MENDES, 2006). No entanto, desde os anos 1990 o fruto passou a ter uma crescente demanda nos mercados nacional e internacional e tornou-se para muitas famílias ribeirinhas a principal fonte de renda.

Muitos autores atribuem esse crescente interesse pelo açaí ao seu alto valor nutricional, atingindo um público específico das academias de ginástica em estados como São Paulo e Rio de Janeiro. Entretanto, a abertura desses mercados deve-se fundamentalmente ao processo de pasteurização e congelamento do açaí garantindo-lhe maior durabilidade ${ }^{30}$.

28 Depoimento de morador da comunidade Bom Jesus.

29 Entrevista com ex-morador do rio Mapuá e atual vereador do munícipio de Breves.

30 A maneira como o açaí é consumido na região Norte tem uma característica particular em relação a sua perecividade e, consequentemente, a sua circulação comercial. Isto é, o açaí batido (in natura) e consumido como "vinho" tem durabilidade de um dia. Esse aspecto confere a economia regional um dinamismo específico quanto a sua cadeia produtiva - desde o produtor que viaja todos os dias das ilhas para vender o fruto nos centros de comercialização nas cidades até o destino final do consumidor. Em Belém, por exemplo, existem 4 mil pontos de venda de açaí, denominado "batedouros". Segundo dados da Secretaria Municipal de Coordenação Geral do Planejamento e Gestão, somente o Porto da Feira do Açaí comercializou mais de 
Nas várzeas do estuário amazônico, o resultado desse crescimento exponencial da venda do açaí, reflete-se de maneira específica na paisagem, cujo processo já é denominado por "açaizamento" 31 . Em certos trechos navegados, observa-se certo padrão na paisagem (muito longe da geometrização das monoculturas), mas uma organização de espécies significativas para a cultura ribeirinha. No rio Jacaré Grande, a cada grupo de 4,5 miritizeiros ${ }^{32}$ (alguns grupos com pouco mais que se juntam com outras, como o murumuru, o tucumã e a bacaba), intercalam-se inúmeros açaizeiros por várzeas densamente povoadas por estas palmeiras em meio a espécies ombrófilas latifoliadas, típicas das florestas de várzea - uma espécie de arquétipo caboclo materializado na paisagem da várzea.

Arquétipo, tanto enquanto modelo ou padrão passível de ser reproduzido, um paradigma caboco ${ }^{33}$, como na rubrica da psicologia como conteúdo imagístico e simbólico do inconsciente coletivo, evidenciável nos mitos e lendas de um povo ou no imaginário individual. Trata-se de uma paisagem que expressa aquilo que Furlan (2006) denomina de "florestas culturais". Segunda a autora, são aquelas florestas manejadas pelas populações rurais,

Particularmente em áreas indígenas, comunidades ribeirinhas, seringueiros, quilombolas, caiçaras entre outros. São espaços sobre os quais as comunidades tradicionais não têm documentos de propriedade privada da terra e a ocupam e usam seus recursos de forma compartilhada (FURLAN, 2006, p. 5).

Neste sentido, as florestas de várzea, ao contrário do entendimento corrente, inclusive o dado pelos órgãos ambientais, enquanto "naturais", como algo dado ou pré-existente, devem ser apreendidas por uma perspectiva históricogeográfica, ou seja, enquanto uma produção cultural de um grupo que tem nas terras alagadiças seus recursos materiais e espirituais ${ }^{34}$.

18.616.000 quilos do produto em 2011. Ver: "Anuário Estatístico do Município de Belém". Disponível em: <http://www.belem.pa.gov.br/app/ANUARIO_2011/ANUARIO\%20 2011\%20COMPLETO.pdf > .

31 A formulação é da professora Oriana Almeida, do Núcleo de Altos estudos Amazônicos (NAEA), da Universidade Federal do Pará (UFPA). Apesar de não encontramos um texto mais detalhado sobre este processo, nota-se que se trata de um manejo contínuo e histórico das florestas de várzea.

32 O miriti apresenta expressiva importância para alguns municípios do estuário amazônico, uma vez que possui todas as suas partes utilizáveis. Os frutos são consumidos in natura, sob a forma de mingaus e derivados como picolé, doces e bolos. Diversos utensílios também são feitos dessa palmeira: paneiro, rasa, tipiti, matapi, peneira, brinquedo, panacarica, arica, maqueira, esteira, paiol, entre outros.

33 Valendo-se da linguagem local, pode-se chegar mais próximo da origem etimológica da palavra caboclo. Há duas hipóteses: kari'boca (filho de branco, no tupi) ou caa-boc, aquele que tem origem na floresta (tupi).

34 Diversas espécies da mata de várzea, assim como outros aspectos que envolvem o ambiente, como a dinâmica das águas, são incorporadas em rituais e cerimônias de pajelança cabocla. 
Estes aspectos, fundamentais para a territorialidade das populações ribeirinhas, em geral, não são reconhecidos pelos dispositivos legais de proteção das florestas, tampouco pelos que reconhecem o direito territorial dessas populações. As longas faixas de várzea do estuário amazônico, assim como outras beiradas e ilhas da Amazônia, vêm se constituindo em uma territorialidade cabocla secular, conformada pelas heranças de um campesinato varzeiro, que tem no extrativismo variado, na pesca, na roça de maniva, na madeira, entre outras formas de manejar aquele ambiente, que afeiçoam o território (de direito) das populações ribeirinhas da Amazônia brasileira.

\section{O RIO MAPUÁ E A "FLORESTA DEITADA”}

Em fins do século XIX, duas famílias atraídas pelas possibilidades econômicas da borracha, fixaram residência nas terras cortadas pelo rio Mapuá e passaram a disputar o controle daquelas várzeas. De um lado, na margem esquerda, Constantino Martins Félix, imigrante português, do outro, Antônio Joaquim Nascimento, migrante de origem cearense, foram pioneiros na exploração da borracha com base no aviamento naqueles lados do Marajó. Como conta um dos herdeiros da família Félix,

Isso foi no ciclo da borracha, quando meu avô veio de Portugal. Chegou aqui ele casou com uma cearense e ficaram aí para dentro do Mapuá. [...] Isso foi no primeiro ciclo [da borracha] e ficaram por aí. Era na época que chamavam do "ouro branco" [...] Quando eles chegaram aqui já tinha gente morando. Tinha um engenho de açúcar. Mas isso faz muito tempo. Eles também eram portugueses ${ }^{35}$.

No final dos anos 1960, já com a "propriedade" nas mãos daquela família, a economia da borracha é substituída pela extração da madeira. Com a vasta cobertura vegetal da região do Marajó, particularmente na região dos Furos de Breves, o comércio de madeira cresce exponencialmente com as exportações de espécies abundantes como virola, andiroba, maçaranduba, cupiuba, entre outras de menor expressão comercial.

Essa riqueza vegetal converteu-se na principal atividade econômica do município, direcionada tanto para o mercado doméstico local e nacional, atingindo, inclusive, escalas de exportação significativas. Na virada da década de 1970 para

Do ponto de vista antropológico, um dos primeiros trabalhos sobre a diversidade religiosa do caboclo amazônico foi a tese de Eduardo Galvão "Santos e visagens: um estudo da vida religiosa de Itá”. A tese resultou na publicação de um livro em 1955 dentro da coleção Brasiliana.

35 Depoimento de um dos herdeiros da família Félix, atual dono de madeireira no rio MapuáMirim. 
1980, multinacionais madeireiras passaram a atuar no município. Destacam-se, tanto em Breves, como nos municípios vizinhos, as empresas Radex e Brumasa, como as principais exportadoras de madeira beneficiada.

Pouco antes da chegada das multinacionais, no início dos anos 1970, já despontavam algumas empresas de porte considerável, como a Superfine Madeireira Ltda., com participação majoritária de capital japonês. Trata-se de um acordo estabelecido com a família Félix, em que a empresa assume o comando da área de 98 mil hectares ${ }^{36}$, às margens do Mapuá, e os "patrões", os Félix, continuavam com o controle da área. No fim da década de 1970, a empresa muda de nome e passa se chamar Santana Madeireira Ltda. e começa a investir em uma fábrica de lambril no município de Santana, estado do Amapá.

A relação estabelecida entre a empresa e os antigos "donos", isto é, o explorador do trabalho no interior das comunidades ribeirinhas, era de responsabilidade mútua. De um lado, enquanto a empresa garantia a compra da madeira, por outro, “o 'patrão' mantinham a relação de subordinação com os extrativistas, por meio de mecanismos de endividamento e dependência [...]" (HERRERA, 2003, p. 61).

Com o fechamento da empresa em 1978, e sem nenhum interesse em manter o controle efetivo da área, essas terras voltam para a responsabilidade dos Félix. Com o encerramento das atividades da empresa e o decorrente abalo à economia local, os conflitos pela posse da terra tornavam-se mais acirrados. Mesmo com os conflitos latentes, o controle das terras permanece com a família Félix que continua a explorar o corte de madeira, porém sem a mesma intensidade com a diminuição da madeira de lei. O episódio foi relatado da seguinte maneira:

Superfine acho que era o nome da empresa deles. Ali em Santo Amaro, na frente de Breves também era deles. [deixa eu ver se entendi: essa família Félix, que tinha essa relação de trabalho com vocês que venderam para a empresa japonesa, mas mesmo assim eles continuaram explorando a área?] Isso, por que a empresa foi e sentou uma fábrica lá perto de Santana [Amapá], numa ilha lá. Aí parece que não deu muito certo e pararam com o negócio da madeira, aí eles [família] ficaram, acho que pagando um aluguel para eles [empresa] ${ }^{37}$.

São diversos os desdobramentos advindos da exploração da madeira, podendo ser exemplificadas em várias dimensões: crescimento demográfico; instalação de serrarias; alteração da cobertura vegetal e o esgotamento de determinadas espécies vegetais - expansão da fronteira de desmatamento;

36 Sobre a imprecisão da dimensão da área ver nota 4 .

37 Depoimento de um morador da comunidade Bom Jesus. 
acentuação da apropriação de terras por empresas privadas; intensiva exploração dos trabalhadores (SOUZA; CANTO; HERRERA, 2002).

\section{O RIO MAPUÁ E A “FLORESTA EM PÉ”}

No início dos anos 2000, retoma-se a discussão sobre a mesma área em função da venda e o controle que passa a ser de uma nova empresa. De acordo com o histórico descrito em documentos da empresa detentora atual da área:

A história recente da Empresa [...] é marcada pela mudança na diretoria da Empresa Santana Madeiras Ltda. Nesses três anos que se seguiram sob uma nova concepção empresarial, a [...] Ltda. (Antiga Santana Madeiras) vem desenvolvendo alguns estudos preliminares que possam subsidiar a formulação de um projeto consistente, ambientalmente correto e socialmente justo, identificado por suas linhas básicas como sendo de desenvolvimento sustentável (ECOMAPUÁ, 2002, p. 2).

O fato foi relatado em uma das entrevistas, da seguinte maneira:

Lá era a fábrica da madeira (Santana), a japonesa, a fábrica que o [nome do novo proprietário] começou tudo isso. Foi lá que o [nome do novo proprietário] conversou com eles e encontrou lá, aí negociaram, ele pagou e ficou com as terras. Assim que aconteceu ${ }^{38}$.

A partir deste momento, a direção da empresa, passa a reivindicar os "legais" direitos da área por meio de novas atividades voltadas para "negócios ambientais" - conforme autodenominado no site da empresa - especificamente com um projeto de REDD+, vinculado ao chamado "mercado de emissões de gases efeito estufa".

As relações entre políticas para mudanças climáticas e pequenos trabalhadores rurais, comunidades tradicionais e indígenas, vêm se estreitando gradativamente a partir dos benefícios que se anunciam pelas diretrizes traçadas para a questão climática global; desde a manutenção das "florestas em pé", enquanto importante sumidouro de carbono da atmosfera até a uma suposta promoção da qualidade socioambiental de famílias que são compensadas por renunciarem, em certos casos, parte da renda de suas atividades regulares. No caso do Mapuá, uma das primeiras medidas tomada pela direção da empresa foi a proibição da exploração madeireira na área.

Aí foi que o chinês veio, ele tornou a proibir a extração de madeira. Só que aí o povo já não era aquele povo antigo, um povo mais novo, aí eles

38 Depoimento de um dos moradores da comunidade Bom Jesus e funcionário da empresa Ecomapuá. 
começaram a achar que não deveriam trabalhar ${ }^{39}$.

Então, aí que veio o japonês vendeu já as terras para o chinês, justamente o [nome do proprietário] foi quem comprou as terras. Por motivo de má compreensão, má entendimento do povo, ele chegou, colocou a proposta dele e aí, e aí o povo se revoltaram. Porque achava que não ia dar certo, porque não ia aceitar, foi um problema muito sério ${ }^{40}$.

Com a proibição do corte da madeira, assim como a exploração do palmito, principais atividades das comunidades do Mapuá, diversos desdobramentos ocorreram gerando controvérsias e disputas em torno das florestas de várzea, originando, inclusive, um rearranjo político e fundiário. Com a chegada da empresa e a partir das medidas proibitivas - obviamente pelas próprias características de seu negócio - foi aberto e circulado um abaixo-assinado pelo Sindicato dos Trabalhadores e Trabalhadoras Rurais (STTR) de Breves para a criação de uma Reserva Extrativista. Como relatado pelo então gestor da RESEX do Mapuá,

Inclusive, depois eu vendo os relatos da história lá, e fui ver que a criação da Reserva, foi justamente por conta da proposta dele inicial. Por que ele é o dono da terra lá, ele comprou de uma antiga madeireira. Aí ele primeiro tentou criar um tipo de reserva de desenvolvimento sustentável em um modelo que pode ter a iniciativa privada lá dentro. Ele chegou a contratar uns consultores para fazer um diagnóstico da área e chegou a fazer uma série de propostas. Mas aí em contrapartida, o pessoal do sindicato se mobilizou e fez um abaixo-assinado contra ele. E daí que surgiu a proposta de uma RESEX, justamente por ele não ter conseguido provar a titularidade dele lá [...]. Isso foi há uns 10 anos atrás que houve esse conflito [...]. Teve até um movimento popular aqui em Breves, com passeata e lutando pela regularização da área. E realmente aconteceu ${ }^{41}$.

Mesmo com as mudanças em relação aos conflitos por terra e pelas florestas do Mapuá - culminando com a criação da RESEX, que abrange grande parte da área adquirida pela empresa -, as disputas pelos recursos das várzeas permanecem.

Desde fevereiro de 2013, a empresa tem aprovado e registrado um projeto no mercado internacional de compensação de gases efeito estufa, mais especificamente pelo Verified Carbon Standard (VCS) ${ }^{42}$, com base em grande parte nos "estoques de carbono" das florestas de várzea do rio Mapuá.

A análise das sobreposições de perspectivas e atuações sobre as várzeas se mostra extremamente complexa, sobretudo no que diz respeito aos direitos dos que ocupam as áreas historicamente. Apesar da complexidade, verifica-se

\footnotetext{
Depoimento de um dos moradores da comunidade Bom Jesus

Depoimento de uma das lideranças da AMOREMA.

41 Depoimento de funcionário do ICMBio.

42 Para maiores detalhes acessar: <http://www.v-c-s.org/>. Acesso em 10 abr. 2014.
} 
um número relativamente pequeno de sujeitos e instituições envolvidas com as disputas sobre as várzeas do Mapuá. Tais disputas estão intrinsecamente vinculadas às visões e maneiras que os diferentes grupos atuam sobre o mesmo ambiente.

Neste sentido, as florestas de várzea, ao contrário do entendimento corrente, inclusive o dado pelos órgãos ambientais, enquanto bens "naturais", como algo dado ou pré-existente, podem ser apreendidas por uma perspectiva histórica, ou seja, enquanto processo cultural de um grupo que tem nas terras alagadiças seus recursos materiais e espirituais. Esse entendimento, isto é, a maneira pela qual o grupo interage e percebe seu ambiente é de extrema importância para as formulações de políticas públicas direcionadas para as áreas de várzea, sobretudo as de regularização fundiária. Há uma dívida histórica a ser paga pelo Estado brasileiro para com essas populações que habitam, a não menos de um século, as várzeas do Marajó.

\section{A VÁRZEA NA PERSPECTIVA DA UNIÃO}

Em uma definição mais técnica, a várzea é caracterizada no artigo 16 do Código de Águas dentro do conceito de solos aluviais ${ }^{43}$. O referido artigo prevê o domínio público do álveo ${ }^{44}$ e margens, considerando os "terrenos de marinha e os terrenos reservados nas margens das correntes públicas de uso comum, bem como dos canais, lagos e lagoas da mesma espécie. Salvo quando as correntes que, não sendo navegáveis nem flutuáveis, concorrem apenas para formar outras simplesmente flutuáveis, e não navegáveis" ${ }^{45}$. Ainda no mesmo artigo, o segundo parágrafo ressalta que "será tolerado o uso desses terrenos pelos ribeirinhos, principalmente os pequenos proprietários, que os cultivem, sempre que o mesmo não colidir por qualquer forma com o interesse público" ${ }^{\text {. }}$.

43 Constitui "aluvião" os acréscimos que sucessiva imperceptivelmente se formarem para a parte do mar e das correntes, aquém do ponto a que chega o preamar médio, ou do ponto médio das enchentes ordinárias, bem como a parte do álveo que se descobrir pelo afastamento das águas. $\int 1^{\circ}$ Os acréscimos que por aluvião, ou artificialmente, se produzirem nas águas públicas ou dominicais, são públicos dominicais, se não estiverem destinados ao uso comum, ou se por algum título legítimo não forem do domínio particular $\ 2^{\circ} \mathrm{A}$ esses acréscimos, com referência aos terrenos reservados, se aplica o que está disposto no art. 11.

44 O mesmo Código define álveo no artigo 9 como "a superfície que as águas cobrem sem transbordar para o solo natural e ordinariamente enxuto".

45 Disponível em: <http://www.planalto.gov.br/ccivil_03/decreto/d24643.htm>. Acesso em: 18 set. 2013.

46 Destaca-se que esse desdobramento do artigo que garante o uso das várzeas por ribeirinhos remonta a 1934, ano de criação do Código de Águas (Decreto n. 24.643, de 10 de julho). Disponível em: < http://www.planalto.gov.br/ccivil_03/decreto/d24643.htm>. Acesso em 18 set. 2013. 
Já a definição dada pela Secretaria do Patrimônio da União, as várzeas são “aquelas áreas compreendidas entre os leitos menor e médio dos rios, cobertas periodicamente por suas águas, e, delimitadas pela Linha do Preamar Médio de 1831 - LPM/1831 ou a Linha Média das Enchentes Ordinárias - LMEO”.

Diante da complexidade de conceituar a várzea, consequentemente de efetivar a regularização dessas áreas habitadas por populações ribeirinhas, cuja concessão de posse demandaria uma melhor definição jurídica desse ambiente, assim como de ilhas federais, foi concebida uma ação de termos de autorização de uso para famílias que ocupam essas áreas historicamente. Em 2005, a SPU publica a Portaria n⿳ 284 que prevê um Termo de Autorização de Uso, específico para o desbaste de açaí e lança um projeto de regularização específico para essas áreas denominado "Nossa Várzea". Quatro anos mais tarde, a SPU amplia o Termo de Autorização de Uso Sustentável (TAUS) individual e coletivo para agroextrativistas da Amazônia Legal. O artigo 1ํ da Portaria nํㅜ 100/2009 prevê:

Disciplinar a utilização e o aproveitamento dos imóveis da União em áreas de várzeas de rios federais na Amazônia Legal em favor das populações ribeirinhas tradicionais, com o objetivo de possibilitar o aproveitamento racional e sustentável dos recursos naturais disponíveis em vista do uso tradicional, voltados à subsistência dessa população, através da concessão de AUTORIZAÇÃO DE USO, a ser conferida em caráter excepcional, transitório e precário.

Ressalta-se a grande importância desta política para o reconhecimento de direitos dessas comunidades historicamente exploradas e esquecidas recorrentemente pelas políticas públicas. Entretanto, para que os direitos territoriais de tais populações sejam efetivamente garantidos, torna-se necessário consolidar o projeto em política estabelecida por lei que reconheça, além de sua importância histórica enquanto ocupantes das áreas de várzea e ilhas federais, as maneiras pelas quais estes grupos percebem e se relacionam com seu meio.

O programa Nossa Várzea, em Breves, começou a realizar os cadastros em meados de março de 2007 e, até o momento, já foram entregues cerca de três mil TAUS no município. Em relação às expectativas sobre os títulos da SPU, alguns moradores ressaltaram a importância do uso do documento como um comprovante de residência, enfatizam seu uso para ter acesso a certos direitos, como aposentadoria, outros indicam sua importância para se obter uma autorização para realizar o manejo adequado do açaí. Todavia, sua função enquanto instrumento de regularização fundiária é pouco citado.

A serventia do SPU é o seguinte: ele não é muito não, de modo que ele é 500 de frente por 1 mil de fundo, então no nosso caso aqui, que tem 3 mil 
e 900 metros a nossa área, só tem serventia mesmo para gente ter porque ele serve para o empréstimo, serve para aposentadoria. Mas é assim, é uma declaração, é só uma declaração. Ele não está dizendo que a gente é dono de nada ${ }^{47}$.

O morador refere-se à maneira como o TAUS é implantado individualmente, "a um raio de até $500 \mathrm{~m}$, a partir de um ponto geodésico georreferenciado estabelecido no local de moradia do requerente, respeitados os limites de tradição das posses existentes no local" (SPU, 2005). Entretanto, fica evidente no depoimento acima que o "respeito aos limites de tradição" não são abarcados pela forma que se delimita a área de uso das famílias pelo termo: "Até 3.300 metros que é minha área, eu tenho que mandar nela. Porque 500 metros como que eu vou sobreviver aqui? Eu só tenho um filho, mas tem muita gente que tem 4, 5 filhos para trabalhar. Não dá para viver num pedacinho desse"48.

As condições dispostas no documento podem gerar, inclusive, problemas de interpretação. Além da projeção do raio de quinhentos metros, o que em termos de área equivale a 78,5hectares, e de considerar os limites tradicionais de posse, o que varia de caso a caso, há também o estabelecimento de uma área estimada autorizada ao uso. Há, portanto, em um mesmo documento três possibilidades de interpretação a respeito da área que o beneficiário poderá utilizar.

Durante as pesquisas de campo, foram frequentes os relatos de desavenças - em função da sobreposição dos raios - entre vizinhos após a emissão dos TAUS. Mesmo com a citação nos termos do respeito aos limites tradicionais de uso e posse, a projeção de um raio de quinhentos metros resulta por criar confusão e falsas expectativas entre os ribeirinhos sobre a área que realmente detém. No caso da comunidade Bom Jesus, os moradores se reuniram para estabelecerem suas áreas, da maneira como as reconhecem historicamente, para que os riscos de conflitos de sobreposição trazidos pela política fossem evitados, conforme relatado em entrevista.

Ficou para o povo da comunidade decidir e [...] pediram que ficasse como tava. Dessa forma que funciona a colocação, que nós tratamos como colocação. No nosso caso foi feito o seguinte: aquele que tivesse duas ou três famílias dentro da casa foi divido entre si. Dividiram tudo de volta para o cunhado dela e para o compadre ela. Dividiram 4 partes. Nós ficamos com 4 partes dividido, mas é uma boa área. Só que eles mexem no que é deles, e eu no que é meu. A divisão é sempre marcada por um igarapé ${ }^{49}$.

\footnotetext{
${ }^{47}$ Entrevista com morador da comunidade Bom Jesus contemplado com o TAUS/SPU.

48 Idem.

49 Idem.
} 
Questionados sobre possíveis conflitos com a empresa detentora da área e se os "donos" teriam o conhecimento da entrega dos TAUS para as comunidades, moradores afirmam não haver mais conflitos - exceto os casos de corte de madeira que passaram a ser proibidos na área, como descrito acima - e que é de total conhecimento a entrega dos documentos da SPU para as famílias residentes na área.

Apesar da importância histórico-geográfica das áreas de várzea, corpos d'água e floresta no modo de vida das populações amazônidas, as definições estabelecidas pela política da SPU são incertas e não apresentam consistência para o reconhecimento dos territórios ribeirinhos.

Assim, é importante considerar alguns aspectos sobre o TAUS quanto a sua importância para a manutenção de populações tradicionais nas áreas de várzea. De que maneira o TAUS pode garantir a segurança fundiária para famílias que habitam e trabalham nas áreas de várzea? A maneira como o terreno individual é dividido e registrado pela política tem contemplado as demandas por terra e recursos dessas famílias? Em outras palavras, a regularização fundiária prevista pelo TAUS abarca os limites de uso tradicional ribeirinho? De que maneira o documento pode assegurar a soberania dos territórios ribeirinhos, frente aos diversos interesses pelos recursos das várzeas? Isto é, de que maneira este documento, ou outras políticas de regularização fundiária na Amazônia, podem assegurar que capitais privados se apropriem indevidamente dos recursos florestais, sejam eles expostos à vista (como a madeira) ou escusos, como o carbono estocado?

\section{CONSIDERAÇÕES FINAIS: A VÁRZEA E DISTINTAS PERCEPÇÕES SOBRE O MESMO AMBIENTE}

Para melhor compreensão sobre os processos históricos constitutivos desses territórios, afeiçoados por populações insulares e varzeiras há séculos, especificamente os que vivem às margens do Mapuá, é de extrema importância que se compreenda as distintas percepções e ações que se sobrepõe nas várzeas do mesmo rio.

O modo pelo qual ocorre a percepção do ambiente externo é discutido por nomes como Claude Lévi-Straus e Gregory Bateson, como bem mostra Tim Ingold em seu livro "The perception of environment". Ambos entendem a mente humana como um processador que decodifica as informações e que estas consistem em padrões de diferença significativa. No entanto, Lévi-Strauss, ao contrário de Bateson, ancora a mente e seu decorrente entendimento do mundo exterior no funcionamento do cérebro. 
Fastening in a more or less arbitrary fashion upon certain elements or distinctive features that are presented to it in the surrounding environment, the mind acts rather like a kaleidoscope, casting them into patterns whose oppositions and symmetries reflect underlying universals of human cognition (INGOLD, 2000, p. 17).

Ingold segue explicando que este mundo, conforme Lévi-Strauss, é estruturado por completo, desde o mais baixo nível de átomos e moléculas, por meio dos níveis intermediários de percepção sensorial, com os mais altos de funcionamento intelectual (Idem). De acordo com Lévi-Strauss,

Quando a mente processa os dados empíricos que recebe previamente processada pelos órgãos e sentidos, ele continua trabalhando estruturalmente o que desde o início já era estrutural. Ele só pode fazê-lo na medida em que a mente, o corpo para que a mente pertence, e as coisas que o corpo e a mente percebem, são parte integrante de uma só realidade (LÉVI-STRAUSS, 1973, p. 21).

Para Bateson, a mente deve ser vista como intrínseca ao sistema de relações organismo-ambiente em que os seres humanos estão enredados necessariamente, ao invés de confinados dentro de corpos individuais, como se estivesse contra uma natureza externa. Ingold cita uma palestra proferida por Bateson em 1970, em que ele sintetiza suas ideias da seguinte maneira: "the mental world - the mind - the world of information processing - is not limited by thes kin" (BATESON apud INGOLD, 2000).

Assim, se para Lévi-Strauss ecologia significa o "mundo exterior" e a mente significa "cérebro", para Bateson, a mente e a ecologia estão situadas nas relações entre o cérebro humano e o ambiente circundante, processo esse que o antropólogo define como uma "ecologia das ideias".

As distintas maneiras pelas quais os grupos humanos interagem, entendem e organizam seus ambientes, como os descritos acima, vêm sendo amplamente debatidas não só pela Antropologia, mas pelas Ciências Humanas como um todo, sobretudo pela Geografia ${ }^{50}$ - cada qual com suas particularidades e métodos específicos de análise.

Sobre as interações mútuas entre "sociedade-natureza”, Marshall Sahlins, ao discutir o trabalho de Gregory Bateson, ressalta que:

Dentro do ecossistema, a trama interativa, ou o subsistema que envolve o homem e seus arredores imediatos, seria caracterizada por relações de retroalimentação (feedback) recíprocas e iguais às existentes entre quaisquer

\footnotetext{
50 Sobre distintas maneiras de percepção do ambiente e a afetividade com o lugar, destaca-se na geografia o conceito de topofilia, elaborado por Yi-Fu Tuan, que denota as relações inerentes entre pessoas e seus lugares. Topus, do grego, significa "lugar", enquanto filo significa amor, amizade, afinidade. Para uma leitura mais completa sobre o conceito ver: Tuan (1980).
} 
outros elementos do circuito, apesar de a transação homem-natureza ser mediada pela cultura. A cultura é aqui, simplesmente, a automediação da natureza (SAHLINS, 2003, p. 94).

As diversas falas, posicionamentos, percepções, registrados durante os trabalhos de campo, mostram a nítida percepção dos elementos que participam e compõem a teia de inter-relações do seu ambiente, algo que se assemelha ao que Bateson (1972), Sahlins (1976) e Ingold (2000) discutem em seus estudos.

Sobre aspectos relacionados a formas contemporâneas em reduzir florestas, ambientes a particularidades funcionais ou utilitárias, como no caso apresentado, Marshal Sahlins ressalta que

A alternativa cibernética prevista pela teoria dos ecossistemas não passa de um fetichismo ecológico mais apropriado ao seu próprio contexto cultural, do capitalismo industrial e burocrático, cujo projeto consiste igualmente em reduzir os homens e as coisas às suas especificações funcionais como elementos de um processo produtivo autodeterminante (SAHLINS, 2003, p. 95).

O exemplo das atividades de REDD+ demonstra uma característica do capitalismo contemporâneo, em que há um maior envolvimento do capital com escalas invisíveis - como em processos de fotossíntese -, implicando um movimento em que porções florestais passam a ser influenciadas por políticas de mudanças climáticas e pelos mercados internacionais de compensação de gases efeito estufa.

A análise das sobreposições de perspectivas e atuações sobre o rio Mapuá se mostra extremamente complexa, sobretudo no que diz respeito aos direitos dos que ocupam as áreas de várzea historicamente.Tais disputas estão intrinsecamente vinculadas às visões e maneiras que os diferentes grupos atuam sobre o mesmo ambiente: 1) camponeses ribeirinhos que tem nas áreas de várzea seu sustento material e espiritual, portanto, parte integrante de sua cultura, de seu território; 2) a Secretaria do Patrimônio da União, apesar do esforço recente em buscar garantir os direitos de uso dos recursos das várzeas para as populações tradicionais ribeirinhas, possui uma visão estritamente técnica sobre este ambiente, em detrimento de um maior aprofundamento em relação à várzea enquanto bem cultural das populações amazônidas; 3) a empresa, com um entendimento utilitarista da floresta, reduz toda a complexidade e diversidade desse ambiente enquanto mero sumidouro de carbono. 
Sobre estes diferentes usos e entendimentos sobre o mesmo ambiente, um dos exemplos favoritos de Bateson (1972) ${ }^{51}$ sobre a interação do homem com a árvore no corte da madeira e retomado por Salhins (2003), nos fazem refletir sobre os diferentes elementos (ou actantes ${ }^{52}$ ) que estão envolvidos de distintas maneiras com a floresta, assim como seus significados são atribuídos conforme as diferentes relações com o ambiente.

O problema é que os homens nunca "cortam madeira" simplesmente dessa forma. Eles cortam toros para as canoas, esculpem as figuras de deuses em clavas guerreiras, ou mesmo cortam madeira para lenha, mas sempre estabelecem relações com a madeira de um modo específico, uma forma cultural, em termos de um projeto significativo cuja finalidade governa os termos da interação recíproca entre o homem e árvore. Se o objetivo é produzir uma canoa, a resposta a uma mudança na arvore é uma; se a meta é a obtenção de lenha, é outra. A resposta ao último golpe depende de um objetivo que não é dado ao processo coma um processo natural; esse golpe e todos os golpes que o antecedem, desde o inicial, dependem da intenção significativa. A interação determinada de árvoreolhos-cérebro-etc. foi estipulada por uma ordem simbólica; é um exemplo paradigmático da natureza subordinada a serviço da cultura (SAHLINS, 2003, p. 95).

Neste sentido, Sahlins chama a atenção para um aspecto central do etnocentrismo, isto é, o homem com seu modo de pensar e agir é apenas uma variável funcional do todo, "um componente reativo em mútua determinação com variáveis ambientais", em que os humanos estão sujeitos às inferências de seu suposto "objeto", o ambiente, vis-a-vis.

Proposições como esta, isto é, que consideram as distintas maneiras de se relacionar com o ambiente, não enquanto objeto a ser apropriado, mas enquanto interlocutor no sentido da reciprocidade entre humanos e não-humanos, nos inspiram a considerar outras formas de avaliação de políticas como a discutida aqui, assim como outras atividades especulativas sobre as florestas que implicam em desdobramentos para populações rurais como as comunidades do rio Mapuá.

Questiona-se, portanto, as implicações que tais ações podem trazer para essas comunidades não apenas do chamado "ponto de vista ambiental" (esse

51 "Consideremos um homem que corta uma arvore com um machado. Cada golpe do machado é modificado ou corrigido, de acordo com a forma do corte da árvore provocada pelo golpe anterior. O processo autocorretivo posto é, mental é realizado par um sistema total, árvoreolhos-cérebro-músculos-machado-golpe-árvore; e é esse sistema total que tem as características da mente imanente" (BATESON apud SAHLINS, 2003, p. 94).

52 Na rubrica da literatura, actante designa ser, força, coisa etc. que participa da ação, na estrutura de uma narrativa. Pela teoria do ator-rede (ANT, sigla em inglês), o termo actante é utilizado como uma forma se referir aos humanos e não humanos de maneira simétrica, considerando que a palavra ator ou sujeito direciona-se simbolicamente apenas aos humanos. 
muito ressaltado tanto pela política da SPU, quanto pelo projeto de REDD+ da empresa), mas da perspectiva cultural de famílias que têm na terra, na floresta e nas águas sua base de reprodução. Reprodução essa de populações que afeiçoam seus territórios de acordo com seus modos de vida, atribuindo significados e formas específicas ao estuário do rio Amazonas há mais de um século.

\section{REFERÊNCIAS}

AB'SABER, A. N. Amazônia: do discurso à práxis. São Paulo: Edusp, [1996] 2001.

AGASSIZ, L. A journey in Brazil. Boston: Ticknor and Fields, 1868.

ALMEIDA, A. W. B. de. Terra de quilombo, terras indígenas, "babaçuais livre", "castanhais do povo", faxinais e fundos de pasto: terras tradicionalmente ocupadas. Manaus: PGSCA-UFAM, 2008.

BATES, H. W. O naturalista no rio Amazonas. Rio de Janeiro: Companhia Editora Nacional, 1944.

BATESON, G. Steps to an ecology of mind. Chicago: The University of Chicago Press, [1972] 2000.

BELÉM. Secretaria Municipal de Coordenação Geral do Planejamento e Gestão. Anuário Estatístico do Município de Belém. v. 16, 2011: Belém: 2012.

BRASIL, Decreto n ${ }^{\circ} 24.643$, de 10 de julho de 1934. Dispõe sobre o Código de Águas. Rio de Janeiro, 10 de julho de 1934.

Código de Águas. Disponível em: <www.planalto.gov.br/ccivil_03/ decreto/d24643.htm>. Acesso em: 18 set. 2013.

Ministério do Planejamento. Secretaria do Patrimônio da União (MP/SPU). Nossa Várzea: cidadania e sustentabilidade na Amazônia brasileira. Brasília, 2005.

Secretaria do Patrimônio da União (SPU). Portaria 284, de 14 de outubro de 2005. Disponível em: <http://patrimoniodetodos. gov.br/pastaarquivo.2009-07-09.3759851862/Portaria\%20284-2005\%20 Autorizacao $\% 20$ de $\% 20$ uso $\% 20$ varzeas $\% 20-\% 20$ Revogada $\% 20$ pela $\% 20$ Portaria\%20100-2009.pdf>. Acesso em: 20 out. 2013.

CASTRO, E. Território, biodiversidade e saberes de populações tradicionais. In: DIEGUES, A. C. (Org.). Etnoconservação. Novos rumos para a proteção da natureza nos trópicos. São Paulo: Annablume; Nupaub-USP, 2000. 
DANIEL, J. Tesouro descoberto no máximo rio Amazonas. Rio de Janeiro: Contraponto, 2004.

DIAS, R.; CARVALHOSA, Z. No Rio das Amazonas. (Filme-vídeo). Produção de Ricardo Dias e Zita Carvalhosa. Direção de Ricardo Dias. São Paulo, 1995. $76 \mathrm{~min}$. son.color. $35 \mathrm{~mm}$.

ECOMAPUÁ CONSERVAÇÃO LTDA. Caracterização da vegetação e uso do solo das terras pertencentes a empresa Ecomapuá Conservação Ltda. no município de Breves/PA. Belém, 2002.

FERREIRA, A. R. Viagem Filosófica pelas Capitanias do Grão-Pará, Rio Negro, Mato Grosso e Cuiabá: 1783-1792. Rio de Janeiro: Conselho Federal de Cultura, 1971. 2 v.

FURLAN, S. A. Florestas culturais: manejo sociocultural, territorialidades e sustentabilidade. Agrária, São Paulo, n. 3, p. 3-15, 2006.

HANSEN, J. A. Para ler as Cartas do Pe. Antonio Vieira. Asas da Palavra, Revista de Letras, Belém: Unama, v. 10, n. 23, 2007.

HÉBETTEE, J. Teoria e prática no estudo do campesinato paraense. In: HÉBETTTE, J.; MAGALHÃES, S. B.; MANESCHY, M. C. (Org.) No mar, nos rios e na fronteira. Faces do campesinato no Pará. Belém: UFPA, 2002.

HÉBETTE, J. Cruzando a fronteira: 30 anos de estudo do campesinato na Amazônia. Belém: Edufpa, 2004.

HERRERA, J. A. Dinâmica e desenvolvimento da agricultura familiar: o caso de Vila Amélia - Breves/Pará. 2003. Dissertação (Mestrado em Agriculturas Familiares e Desenvolvimento Sustentável) - Centro de Ciências Agrárias/ Universidade Federal do Pará e EMPRABA, Belém, 2003.

INGOLD, T. The perception of environment. Essays of livehood, dwelling and skill. London; New York: Routledge, 2000.

LEITE, S. História da Companhia de Jesus no Brasil. Rio de Janeiro: Instituto Nacional do Livro, 1943.

LÉVI-STRAUSS, C. Antropologia estrutural dois. Rio de Janeiro: Tempo Brasileiro, 1993.

Structuralism and ecology. Social Science Information, v. 12, n. 1, p. $7-23,1973$. 
LIMA, A. Amazônia, a terra e o homem. São Paulo: Editora Nacional, [1933], 1975. (Coleção Brasiliana)

MARTINS, C. P.; SCHAAN, D. P.; SILVA, W. F. Arqueologia do Marajó das florestas. Fragmentos de um desafio. In: SACHAAN, D.; MARTINS, C. P. (Org.) Muito além dos campos: arqueologia e história na Amazônia Marajoara. Belém: GKNORONHA, 2010.

MCGRATH, D. Parceiros no Crime: o regatão e a resistência cabocla na Amazônia tradicional. Novos Cadernos NAEA, Belém, v. 2, n. 2, p. 57-72, 1999.

OCDE - Organização para a Cooperação e Desenvolvimento Econômico. Environmental goods and services. An assessement of the environmental, economic and development benefits of further global and trade liberalisation. Paris, 2000.

OLIVEIRA Jr., P. H. B. Ribeirinhos e roceiros. Gênese, subordinação e resistência camponesa em Gurupá. 1991. Dissertação. Faculdade de Filosofia, Letras e Ciências Humanas, Universidade de São Paulo, São Paulo, 1991.

PACHECO, A. S. A Conquista do ocidente marajoara: índios, portugueses e religiosos em reinvenções históricas. In: SACHAAN, D.; MARTINS, C. P. (Org.) Muito além dos campos: arqueologia e história na Amazônia Marajoara. Belém: GKNORONHA, 2010.

PEREIRA, J. V. Atualidade de Antônio Vieira na Amazônia: uma controvérsia do século XVI para reanimar o século XXI. Asas da Palavra. Revista de Letras, Belém: Unama, v. 10, n. 23, 2007.

SAHLINS, M. Cultura e razão prática. Rio de Janeiro: Jorge Zahar, [1976] 2003.

SANTANA, A. C.; CARVALHO, D. F; MENDES, F. A. T. Organização e competitividade das empresas de polpas de frutas no Estado do Pará: 1995 a 2004. Belém: Unama, 2006.

SANTOS, R. de A. de O. História Econômica da Amazônia: 1800-1920. São Paulo: T. A. Queiroz, 1980.

SANTOS, B. de S.; MENESES, M. P. (Orgs.). São Paulo; Editora Cortez. Abril de 2011. Resenha de: OLIVEIRA, A. C. Epistemologias do Sul. Revista Espaço Acadêmico, no 119, p. 637, abril de 2011.

SHANIN, T. A definição de camponês: conceituações e desconceituações. Estudos CEBRAP, São Paulo, n. 26, 1980. 
SOUZA, A. L. de; CANTO, O. do; HERRERA, J. A. Comunidades agroextrativistas do rio Mapuá - Breves/PA. Belém: UFPA, 2002 (Diagnóstico Socio-Econômico. Convênio 518 - Nova Amafrutas/FADESP/UFPA).

TOCANTINS, L. O rio comanda a vida. Uma interpretação da Amazônia. Rio de Janeiro: Civilização Brasileira, 1961.

TUAN, Y. Topofilia. Um estudo da percepção, atitudes e valores do meio ambiente. Rio Claro: Difel, 1980.

VIEIRA, A. Cartas do P. Antonio Vieira da Companhia de Jesus. Tomo II. 1. ed. Lisboa: Officina da Congregação do Oratorio, 1735.

. História do futuro. Livro anteprimeyro. Lisboa: Officina de Antonio Pedrozo Galram, 1718. 